\title{
Oxidative Phosphorylation
}

\author{
THE EFFECT OF ANIONS ON THE INHIBITION BY TRIETHYLTIN \\ OF VARIOUS MITOCHONDRIAL FUNCTIONS, AND THE RELATIONSHIP \\ BETWEEN THIS INHIBITION AND BINDING OF TRIETHYLTIN
}

\author{
By M. S. ROSE* and W. N. ALDRIDGE \\ Biochemical Mechanisms Section, Toxicology Unit, Medical Research Council Laboratories, \\ Woodmansterne Road, Carshalton, Surrey, U.K.
}

(Received 1 November 1971)

\begin{abstract}
1. The binding of triethyltin to rat liver mitochondria is unaffected by the nature of the predominant anion in the incubation medium. 2. With chloride, bromide or iodide as the predominant anion, ATP synthesis linked to the oxidation of pyruvate or succinate and ATP hydrolysis stimulated by 2,4-dinitrophenol are much more sensitive to triethyltin than they are when nitrate or isethionate is the predominant anion. 3. When nitrate or isethionate is the predominant anion, oxygen uptake stimulated by 2,4-dinitrophenol is not inhibited by triethyltin. 4. In the presence of nitrate or isethionate anions, inhibition of ATP synthesis is directly related to the binding of triethyltin to mitochondria. 5. The relationship of the above effects to the anion-hydroxide ion exchange mediated by triethyltin and the relevance of this to published arrangements for coupling of electron transport to ATP synthesis are discussed.
\end{abstract}

The binding of triethyltin to rat liver mitochondria has been described in terms of two binding sites, one (binding site 1) with an affinity of $10^{5}-10^{6} \mathrm{M}^{-1}$ and the other of lower affinity (Aldridge \& Street, 1970). The relationship between binding to this site and the inhibition of oxidative phosphorylation is complex (Aldridge \& Street, 1971). An interpretation of this relationship, based on the assumption that triethyltin brings about its biochemical effects by reaction with this binding site, has been proposed by Aldridge \& Rose (1969).

An important advance in this field of study is the demonstration (Selwyn et al., 1970a; Stockdale et al., 1970) that trialkyltins can mediate the transport across mitochondrial membranes of halide and thiocyanate ions in exchange for hydroxide ions. The influence of different anions on the effects of triethyltin on various mitochondrial functions has been examined. There is now no doubt that triethyltin exerts effects on oxidative phosphorylation by at least two different mechanisms.

\section{Materials and Methods}

\section{Materials}

Special chemicals. Triethyltin sulphate was prepared from triethyltin hydroxide supplied by the Tin Research Institute, Greenford, Middlesex, U.K., as described by Aldridge \& Cremer (1955). Triethyltin

* Present address: I.C.I. Ltd., Industrial Hygiene Laboratories, Alderley Park, Cheshire SK10 4TJ, U.K. chloride labelled with ${ }^{113} \mathrm{Sn}$ (specific radioactivity $6 \mathrm{mCi} / \mathrm{mmol}$ ) was purchased from The Radiochemical Centre, Amersham, Bucks., U.K. The following were purchased: rotenone, glycylglycine and 2,4-dinitrophenol from BDH Chemicals Ltd., Poole, Dorset, U.K.; ATP, sodium pyruvate and hexokinase (yeast) from Sigma Chemical Co., St. Louis, Mo., U.S.A.; $N N N^{\prime} N^{\prime}$-tetramethyl-p-phenylenediamine hydrochloride from Kodak Ltd., London, U.K., and sodium hydroxyethanesulphonate (isethionate) from Koch-Light Laboratories Ltd., Colnbrook, Bucks., U.K. Rotenone was recrystallized from ethanolwater. $N N N^{\prime} N^{\prime}$-Tetramethyl-p-phenylenediamine hydrochloride was purified as described by Aldridge \& Street (1971). Sodium isethionate was converted into the potassium salt by passage down Bio-Rad cation-exchange resin (AG50W X8; $\mathrm{H}^{+}$form) and neutralization with $\mathrm{KOH}$. All other reagents were of A.R. grade.

\section{Methods}

Preparation of the mitochondrial fraction. Rat liver mitochondria were prepared as described by Aldridge \& Street (1971). They were suspended in $0.3 \mathrm{M}$-sucrose at a protein concentration of $20-25 \mathrm{mg} / \mathrm{ml}$.

Measurement of triethyltin binding. Rat liver mitochondria were incubated at $37^{\circ} \mathrm{C}$ for $5 \mathrm{~min}$ in the various media described for the measurement of ATP synthesis (but with $6.7 \mathrm{~mm}$-phosphate) containing triethyl[ $\left.{ }^{113} \mathrm{Sn}\right]$ tin and then treated as described by Aldridge \& Street (1970). 
Measurement of ATP synthesis. ATP synthesis over 2 or $4 \mathrm{~min}$ was determined by measuring $P_{i}$ uptake in the presence of hexokinase and glucose as described by Aldridge \& Street (1971). The medium used contained (final concentrations) $\mathrm{KCl}(0.1 \mathrm{M})$, $\mathrm{Mg}\left(\mathrm{NO}_{3}\right)_{2}(14 \mathrm{mM})$, EDTA (1 mM), potassium phosphate $(1.33 \mathrm{~mm})$, ATP $(2.3 \mathrm{~mm})$, glucose $(60 \mathrm{~mm})$, glycylglycine $(16.7 \mathrm{~mm})$, sucrose $(15 \mathrm{~mm})$ and hexokinase (capable of converting ATP into ADP at $40 \mu \mathrm{mol} / \mathrm{min}$ at $25^{\circ} \mathrm{C}$ ). This medium differs from that used previously (Aldridge \& Street, 1971) in having a lower phosphate concentration. This was shown to have no effect on mitochondrial function. When nonchloride media were used, the $\mathrm{KCl}$ was replaced by $\mathrm{KI}(0.1 \mathrm{M})$ or $\mathrm{KBr}(0.1 \mathrm{M})$ or $\mathrm{KSCN}(0.1 \mathrm{M})$ or $\mathrm{KNO}_{3}$ $(0.1 \mathrm{M})$ or potassium isethionate $(0.1 \mathrm{M})$. Substrates used were pyruvate $(10 \mathrm{~mm})+$ fumarate $(1 \mathrm{~mm})$ or succinate $(10 \mathrm{mM})+$ rotenone $(1.1 \mu \mathrm{M})$ or ascorbate $(40 \mathrm{~mm})+N N N^{\prime} N^{\prime}$-tetramethyl - $p$-phenylenediamine hydrochloride (1 mM).

Measurement of $\mathrm{O}_{2}$ uptake. $\mathrm{O}_{2}$ uptake was measured polarographically in a total volume of $1.0 \mathrm{ml}$. The media used were as described for the measurement of ATP synthesis with the omission of hexokinase and glucose.

Measurement of ATP hydrolysis. ATP hydrolysis was measured in a medium $(3 \mathrm{ml})$ that contained (final concentrations) $\mathrm{KCl}(0.1 \mathrm{M}), \mathrm{Mg}\left(\mathrm{NO}_{3}\right)_{2}(14 \mathrm{~mm})$, EDTA (1 mM), ATP (3 mM), glycylglycine (16.7 mM), rotenone $(1.1 \mu \mathrm{M})$ and sucrose $(15 \mathrm{mM})$, as described by Aldridge \& Street (1971). When non-chloride media were used the $\mathrm{KCl}$ was replaced by $0.1 \mathrm{M}$ potassium salts as described for ATP synthesis.

Measurement of mitochondrial swelling. Mitochondria $(0.05 \mathrm{ml})$ were added to medium $(2.85 \mathrm{ml})$ plus $0.3 \mathrm{M}$-sucrose $(0.1 \mathrm{ml})$ and incubated at $37^{\circ} \mathrm{C}$ with shaking. At various times up to $10 \mathrm{~min}$ the $E_{550}$ was measured. The mitochondrial protein concentration in the incubation medium was $0.3-0.5 \mathrm{mg} / \mathrm{ml}$.

Inhibitors. Triethyltin sulphate and 2,4-dinitrophenol were used as solutions in water. Rotenone was used as a solution in dimethylformamide.

Analytical methods. $\mathrm{P}_{\mathrm{i}}$ was measured by the method of Fiske \& SubbaRow (1925) as described by Aldridge \& Street (1971). Protein was measured by the biuret method of Robinson \& Hogden (1940) as modified by Aldridge (1962).

\section{Results}

Rates of various mitochondrial functions in different media

ATP synthesis, ATP hydrolysis and $\mathrm{O}_{2}$ uptake in the presence and in the absence of $20 \mu \mathrm{M}$-2,4-dinitrophenol were examined in media in which the bulk constituent had been changed (Table 1). When the predominant constituent was $\mathrm{KNO}_{3}$ or potassium

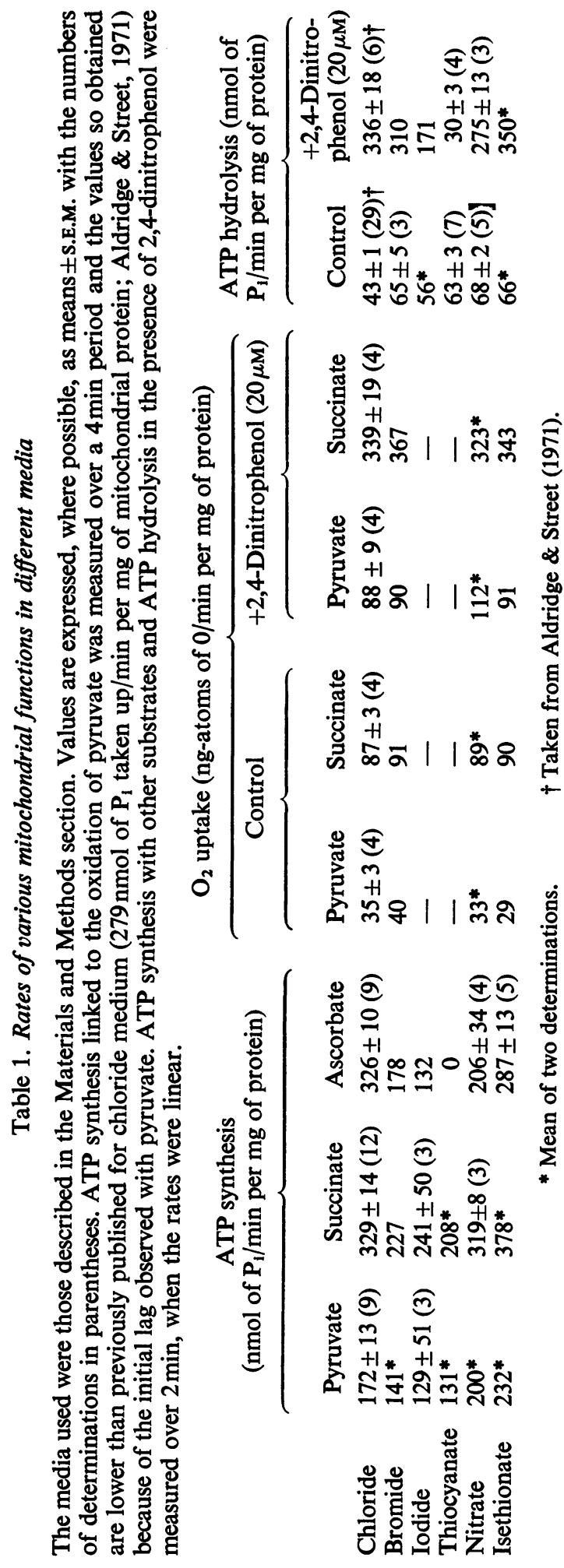


isethionate, rates comparable with those found in $\mathrm{KCl}$ media were obtained (Table 1). Replacement of chloride by other anions, however, often resulted in lower rates or even failure to demonstrate certain functions. In particular, when thiocyanate was the predominant anion, there was no synthesis of ATP linked to the oxidation of ascorbate and no stimulation of ATP hydrolysis by 2,4-dinitrophenol (Table 1).

\section{Effect of anions on the distribution of triethyltin between chloroform and water}

Increasing concentrations of chloride, bromide, iodide and thiocyanate ions increase the distribution of triethyltin between chloroform and aqueous medium in favour of the chloroform (Fig. 1). In contrast, increasing concentrations of nitrate and isethionate have no effect.

\section{Effect of anions on ATP hydrolysis in the presence of triethyltin}

In a medium containing chloride, ATP hydrolysis is first increased and then decreased as the concentration of triethyltin is increased (Aldridge \& Street, 1964, 1971). When chloride is replaced by bromide or iodide the same behaviour is observed (Fig. 2). When KSCN is the main constituent of the medium, little stimulation of ATP hydrolysis is observed. This lack of effect (Fig. 2) may be associated with the inability of 2,4-dinitrophenol to stimulate ATP hydrolysis in a thiocyanate-containing medium (Table 1). In contrast with the results obtained in halide-containing media, there is no stimulation of ATP hydrolysis in media that contain nitrate or isethionate as the main constituent (Fig. 2).

\section{Effect of anions on $\mathrm{O}_{2}$ uptake in the presence of triethyltin}

Triethyltin in a chloride-containing medium stimulates $\mathrm{O}_{2}$ uptake with either pyruvate or succinate as substrate, and this occurs with the same concentrations that stimulate ATP hydrolysis (Aldridge \& Street, 1964, 1971). In media that contain nitrate or isethionate instead of chloride there is no stimulation of $\mathrm{O}_{2}$ uptake, in agreement with the lack of stimulation of ATP hydrolysis (Fig. 2 and Table 2).

Effects of anions on the inhibition by triethyltin of $\mathrm{O}_{2}$ uptake in the presence of 2,4-dinitrophenol

Triethyltin, in chloride- or bromide-containing media, inhibits $\mathrm{O}_{2}$ uptake stimulated by 2,4-dinitrophenol (Fig. 3; Aldridge, 1958; Aldridge \& Street, 1971) when either pyruvate or succinate is used as

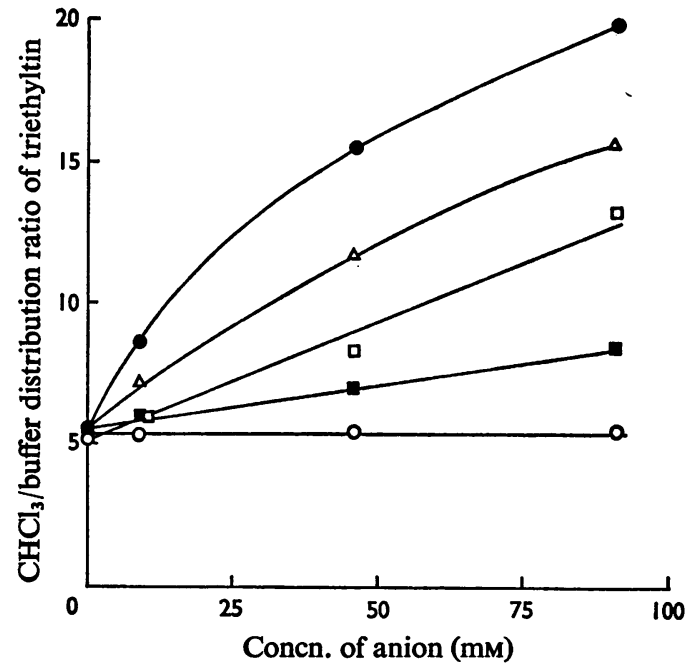

Fig. 1. Effect of anions on the distribution of triethyltin into chloroform

Small volumes $(0.05-0.3 \mathrm{ml})$ of $1 \mathrm{M}$ stock salt solutions ( $\square$, chloride; $\square$, bromide; $\bullet$, iodide; $\Delta$, thiocyanate; 0 , nitrate or isethionate) were added to $0.1 \mathrm{M}$-trisnitrate buffer, $\mathrm{pH} 7.0(3.0 \mathrm{ml})$. The total volume of the buffer phase was kept at $3.3 \mathrm{ml}$ by addition of the required volume of $1 \mathrm{M}-\mathrm{KNO}_{3}$. After addition of chloroform $(3.0 \mathrm{ml}), 100 \mathrm{nmol}$ of triethyltin (approx. $0.2 \mu \mathrm{Ci}$ ) was added in $0.05 \mathrm{ml}$ and the tubes were shaken vigorously for $10 \mathrm{~s}$. The layers were separated by centrifugation and $0.5 \mathrm{ml}$ samples of each were taken for measurement of radioactivity.

substrate. Stockdale et al. (1970) have, however, reported that, in a medium containing sucrose and free from chloride ions, tri-n-propyltin does not inhibit $\mathrm{O}_{2}$ uptake (with succinate as substrate) stimulated by 2,4-dinitrophenol. Inhibition was obtained in a chloride-containing medium, but was found to be time-dependent (see also Sone \& Hagihara, 1964). It was concluded that the inhibition in a chloride-containing medium was a consequence of damage to the mitochondria caused by swelling. In contrast with this view, in other media containing chloride, onset of inhibition is immediate and the rate is linear (Aldridge \& Street, 1971). In addition, the results in Table 3 show that no additional swelling occurs even with $1.33 \mu \mathrm{M}$-triethyltin, a concentration that will inhibit $\mathrm{O}_{2}$ uptake stimulated by 2,4-dinitrophenol by more than $80 \%$ (Fig. 3; Aldridge \& Street, 1971). In nitrate- or isethionate-containing media, the extent of swelling is little different from that in halide-containing media (Table 3), but the inhibition of 2,4-dinitrophenol-stimulated $\mathrm{O}_{2}$ uptake is small

Vol. 127 
even at concentrations as high as $27 \mu \mathrm{M}$ (Fig. 3). In these experiments with different media, no correlation can be made between swelling and inhibition by triethyltin of $\mathrm{O}_{2}$ uptake stimulated by 2,4-dinitrophenol.

\section{Effect of anions on the binding of triethyltin to intact mitochondria}

Previous measurements of triethyltin binding to mitochondria or mitochondrial fractions have been made in chloride-containing media (Aldridge \&

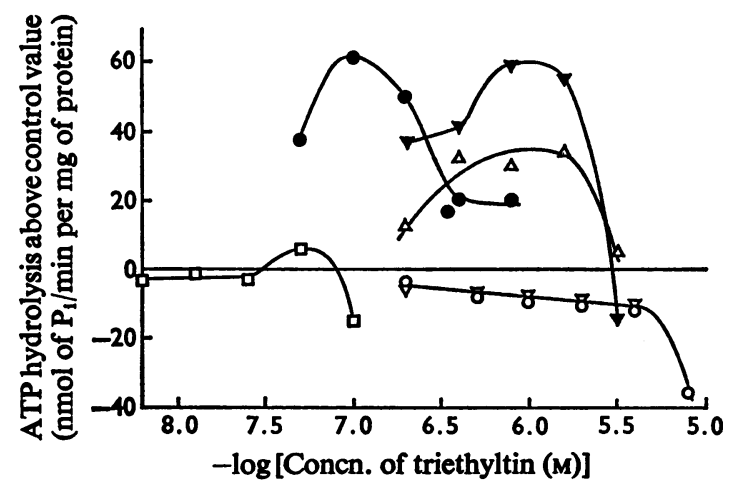

Fig. 2. Effect of anions on ATP hydrolysis stimulated by triethyltin

All measurements were made in the presence of rotenone with the same preparation of mitochondria, as described in the Materials and Methods section. The results given are the means of duplicate experiments and are ATP hydrolysis stimulated by triethyltin in the presence of thiocyanate ( $\square$ ), iodide $(\bullet)$, bromide $(\nabla)$, chloride $(\Delta)$, nitrate $(0)$ and isethionate $(\nabla)$.
Street, 1970, 1971). Determinations of the binding of triethyltin to intact mitochondria have now been made in a variety of media. The results in each medium can be analysed on the basis of two classes of binding sites; the concentrations of and affinity constants for these sites are given in Table 4. The concentration of sites and affinity for triethyltin of these sites is unaffected by the replacement of chloride by bromide or nitrate or isethionate ion (Table 4).

Triethyltin also binds to rat haemoglobin (Rose \& Aldridge, 1968; Rose, 1969). Previous measurements of the number of binding sites and affinity of these sites have been made in buffers containing chloride ion, an anion shown to effect the solubility of triethyltin in chloroform (Fig. 1). Replacement of the chloride ion by nitrate ion has no effect on these binding constants (Table 4).

Thus the binding of triethyltin to mitochondria and to rat haemoglobin is unaffected by the anionic composition of the medium and is unaffected by anions that increase the solubility of triethyltin in chloroform.

Relationship between inhibition of mitochondrial function and binding of triethyltin to mitochondria

In media containing chloride, ATP synthesis linked to the oxidation of pyruvate or succinate and ATP hydrolysis and $\mathrm{O}_{2}$ uptake stimulated by 2,4-dinitrophenol are all inhibited by similar concentrations of triethyltin (Aldridge \& Street, 1971). The inhibition obtained was approximately ten times that expected from the extent of binding site 1 complexed. In contrast, the percentage inhibition of ATP synthesis linked to the oxidation of cytochrome $c$ and the percentage of binding site 1 complexed were approximately equal (Aldridge \& Street, 1971).

In media that contain bromide, iodide or thio-

\section{Table 2. Stimulation of mitochondrial respiration by triethyltin}

Respiration in the presence and absence of triethyltin was measured by using an oxygen electrode as described in the Materials and Methods section.

$$
\mathrm{O}_{2} \text { uptake (ng-atoms of } \mathrm{O} / \mathrm{min} \text { per } \mathrm{mg} \text { of protein) }
$$

\begin{tabular}{|c|c|c|c|c|c|c|}
\hline \multirow{2}{*}{$\begin{array}{l}\text { Concn. of } \\
\text { triethyltin }(\mu \mathrm{M})\end{array}$} & \multicolumn{2}{|c|}{ Isethionate } & \multicolumn{2}{|c|}{ Nitrate } & \multicolumn{2}{|c|}{ Chloride } \\
\hline & Pyruvate & Succinate & Pyruvate & Succinate & Pyruvate & Succinate \\
\hline 0 (control) & 29 & 90 & 29 & 80 & 37 & 84 \\
\hline 0.1 & - & - & - & - & 39 & 92 \\
\hline 0.25 & - & - & - & - & 45 & 102 \\
\hline 0.33 & 29 & 98 & - & - & - & - \\
\hline 0.5 & - & - & - & - & 53 & 119 \\
\hline 1.0 & - & 98 & 29 & - & 59 & 131 \\
\hline 3.0 & 29 & 98 & 29 & 80 & 68 & - \\
\hline 9.0 & 29 & 98 & 36 & 88 & 60 & - \\
\hline
\end{tabular}




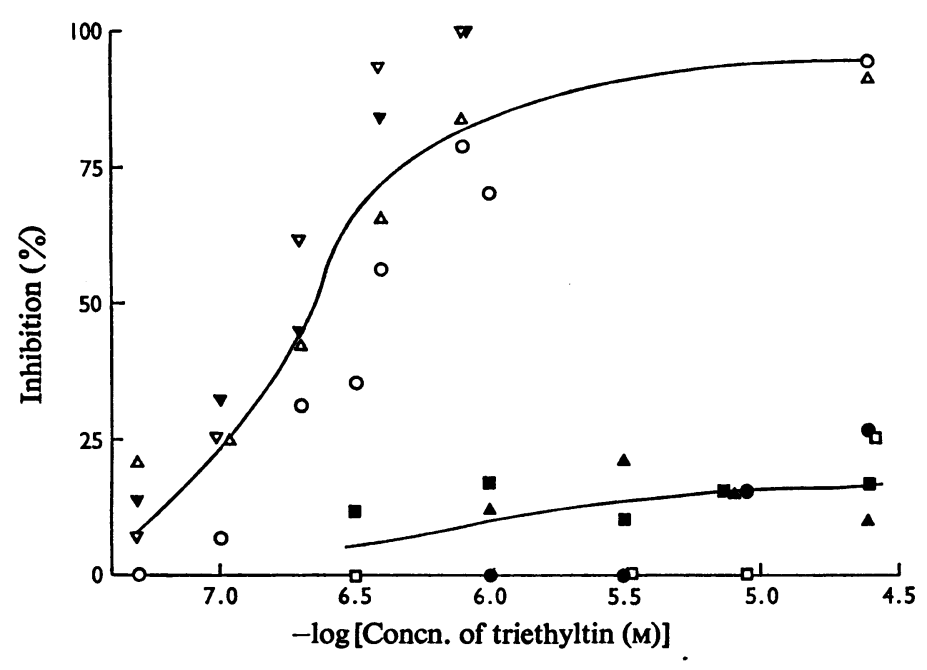

Fig. 3. Effect of different media on the inhibition by triethyltin of mitochondrial respiration stimulated by 2,4-dinitrophenol

Mitochondrial respiration was measured with an oxygen electrode as described in the Materials and Methods section. The results are expressed as percentage inhibition of the value obtained in the presence of 2,4-dinitrophenol $(20 \mu \mathrm{M})$ in the absence of triethyltin. The symbols are: inhibition of pyruvate oxidation in chloride (0), bromide $(\nabla)$, nitrate $(\bullet)$, isethionate $(\square)$; inhibition of succinate oxidation in chloride $(\Delta)$, bromide $(\nabla)$, nitrate $(\Delta)$ and isethionate $(\square),-\log 4.5$ is equivalent to approx. $90 \%$ saturation of binding site 1 .

\section{Table 3. Mitochondrial swelling in different media}

Mitochondrial swelling in the media and conditions used for the measurement of ATP synthesis was measured as described in the Materials and Methods section. The triethyltin concentrations were as follows: chloridecontaining medium, $1.33 \mu \mathrm{M}$; bromide- and iodide-containing media, $0.4 \mu \mathrm{M}$; nitrate- and isethionate-containing media, $3 \mu \mathrm{M}$. Mitochondria incubated in $67 \mathrm{~mm}$-phosphate buffer, $\mathrm{pH} 6.8$, under similar conditions gave a value for $-\Delta E_{550}$ in $10 \mathrm{~min}$ of 0.76 , most of this change occurring in the first few minutes.

\begin{tabular}{|c|c|c|c|}
\hline \multirow[b]{2}{*}{ Anion } & \multirow{2}{*}{$\begin{array}{l}\text { Compound } \\
\text { oxidized in } \\
\text { medium }\end{array}$} & \multicolumn{2}{|c|}{$-\Delta E_{550}(0-10 \mathrm{~min})$} \\
\hline & & Control & $\begin{array}{l}\text { Additional swelling in } \\
\text { the presence of triethyltin }\end{array}$ \\
\hline Chloride & $\begin{array}{l}\text { Pyruvate } \\
\text { Succinate } \\
\text { Ascorbate }\end{array}$ & $\begin{array}{l}0.33 \\
0.26 \\
0.28\end{array}$ & $\begin{array}{l}0 \\
0 \\
0.12\end{array}$ \\
\hline Bromide & $\begin{array}{l}\text { Pyruvate } \\
\text { Succinate } \\
\text { Ascorbate }\end{array}$ & $\begin{array}{l}0.30 \\
0.10 \\
0.08\end{array}$ & $\begin{array}{l}0 \\
0.01 \\
0.22\end{array}$ \\
\hline Iodide & $\begin{array}{l}\text { Pyruvate } \\
\text { Succinate } \\
\text { Ascorbate }\end{array}$ & $\begin{array}{l}0.46 \\
0.47 \\
0.39\end{array}$ & $\begin{array}{l}0 \\
0 \\
0.10\end{array}$ \\
\hline Nitrate & $\begin{array}{l}\text { Pyruvate } \\
\text { Succinate } \\
\text { Ascorbate }\end{array}$ & $\begin{array}{l}0.37 \\
0.20 \\
0.18\end{array}$ & $\begin{array}{l}0.04 \\
0 \\
0.07\end{array}$ \\
\hline Isethionate & $\begin{array}{l}\text { Pyruvate } \\
\text { Succinate } \\
\text { Ascorbate }\end{array}$ & $\begin{array}{l}0.46 \\
0.40 \\
0.44\end{array}$ & $\begin{array}{l}0 \\
0.01 \\
0.02\end{array}$ \\
\hline
\end{tabular}

Vol. 127 


\section{Table 4. Effect of different media on the binding of triethyltin to mitochondria and to haemoglobin}

Mitochondrial binding measurements were done in different media as described in the Materials and Methods section and the constants were defined and calculated as described by Aldridge \& Street (1970). Binding of triethyltin to rat haemoglobin was measured as described by Rose (1969). Values are expressed, where possible, as means \pm S.E.M. with the numbers of determinations in parentheses.

Binding to intact mitochondria

\begin{tabular}{|c|c|c|c|c|c|}
\hline Anion & Use of medium & $\begin{array}{c}n_{1}(\mathrm{nmol} / \mathrm{mg} \\
\text { of protein) }\end{array}$ & $K_{1}\left(\mu \mathrm{M}^{-1}\right)$ & $\begin{array}{c}n_{2}(\mathrm{nmol} / \mathrm{mg} \\
\text { of protein) }\end{array}$ & $K_{2}\left(\mu M^{-1}\right)$ \\
\hline \multirow[t]{3}{*}{ Chloride } & ATP hydrolysis & $1.08 \pm 0.03(4)$ & $0.33 \pm 0.01(4)$ & $48 \pm 5(4)$ & $0.002 \pm 0.0001$ \\
\hline & Pyruvate oxidation & $1.13^{*}$ & $0.33^{*}$ & $46^{*}-10$ & $0.002^{*}$ \\
\hline & Succinate oxidation & 1.16 & 0.33 & 48 & 0.002 \\
\hline Bromide & ATP hydrolysis & 1.03 & 0.33 & 60 & 0.002 \\
\hline \multirow[t]{2}{*}{ Nitrate } & ATP hydrolysis & 1.0 & 0.29 & 66 & 0.0018 \\
\hline & Pyruvate oxidation & $1.05^{*}$ & $0.32^{*}$ & $55^{*}$ & $0.0015^{*}$ \\
\hline Isethionate & Pyruvate oxidation & $1.0^{*}$ & $0.32^{*}$ & $43^{*}$ & $0.0018^{*}$ \\
\hline \multicolumn{6}{|c|}{ Binding to rat haemoglobin } \\
\hline Anion & of haemoglobin) & $K\left(\mu \mathrm{M}^{-1}\right)$ & & & \\
\hline Chloride & 2.2 & 0.72 & & & \\
\hline Nitrate & 2.2 & 0.66 & & & \\
\hline & & * Mean of tw & erminations. & & \\
\hline
\end{tabular}

cyanate, ATP synthesis linked to the oxidation of succinate is more sensitive to triethyltin than in a chloride-containing medium, and the relationship between inhibition and binding to site 1 approaches 50:1 (Fig. 4). ATP synthesis linked to the oxidation of pyruvate in a bromide-containing medium has a similar sensitivity (Fig. 4). Thus, in a chloridecontaining medium, the sensitivity to triethyltin of ATP synthesis linked to the oxidation of pyruvate or succinate is the same, and is greater than the sensitivity of ATP synthesis linked to the oxidation of ascorbate. The results in Fig. 4, together with the results of other experiments, indicate that this is also true in media that contain bromide or iodide anions. Similarly, ATP hydrolysis stimulated by 2,4-dinitrophenol is much more sensitive to triethyltin than ATP synthesis linked to the oxidation of ascorbate in these media.

When chloride is replaced by nitrate or isethionate, ATP synthesis linked to the oxidation of pyruvate or succinate is less inhibited by triethyltin than in chloride-containing media. The extent of inhibition of phosphorylation linked to the oxidation of these two substrates is the same as that linked to the oxidation of ascorbate (Fig. 5), i.e. $100 \%$ inhibition is obtained as $100 \%$ complexing of binding site 1 is approached. The inhibition by triethyltin of ATP hydrolysis stimulated by 2,4-dinitrophenol in a nitrate- or isethionate-containing medium is, however, greater than that expected from the extent of binding site 1 complexed (Fig. 6), 100\% inhibition occurring at approx. $50 \%$ of binding site 1 complexed.

\section{Discussion}

In making comparisons of the effects of inhibitors on mitochondrial function in different media, it is important to maintain the basic composition of the medium as constant as possible. The media used in this work are derived from the media described previously (Aldridge, 1957; Aldridge \& Street, 1971) by the replacement of the main component $(0.1 \mathrm{M}-\mathrm{KCl})$ by equivalent concentrations of other anions and the use of $\mathrm{Mg}\left(\mathrm{NO}_{3}\right)_{2}$ in place of $\mathrm{MgCl}_{2}$. Some anions had deleterious effects on mitochondrial function (Table 1). 0.25M-Sucrose and anions such as lactate or glycerate were also tried in place of $\mathrm{KCl}$, but none of these was as satisfactory as nitrate or isethionate. The latter anion was chosen, as it has been shown not to penetrate mitochondria very readily (Selwyn $e t$ al., 1970b). Glycerol 2-phosphate has been used by Holland \& Sherratt (1971), but it is not satisfactory for our purpose because, at the high concentrations used, it will complex triethyltin (M. S. Rose, unpublished work), as found for phosphate (Rose, 1969).

The binding of triethyltin to mitochondria and to rat haemoglobin is unaffected by different anions (Table 4). However, a number of mitochondrial functions are much more sensitive to triethyltin in the presence of halide and thiocyanate ions (Figs. 3 and 


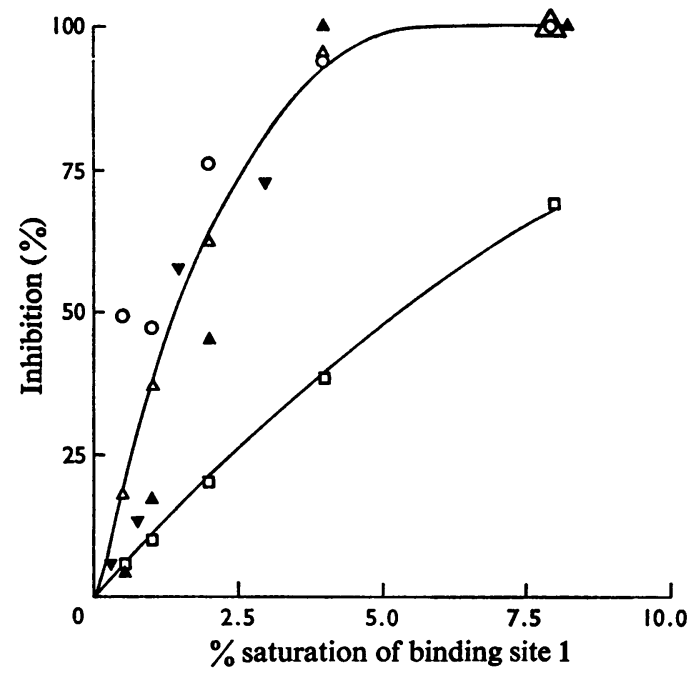

Fig. 4. Relationship between percentage inhibition of ATP synthesis by triethyltin and percentage saturation of binding site 1 in iodide-, bromide-, chloride- and thiocyanate-containing media

The results were obtained as described in the Materials and Methods section. Percentage saturation of binding site 1 was calculated as described by Aldridge \& Street (1971) by using the data in Table 4. The symbols are: ATP synthesis linked to oxidation of succinate in chloride-containing medium ( $\square$ ), bromide-containing medium $(\Delta)$, iodide-containing medium $(\Delta)$ and thiocyanate-containing medium $(\nabla)$; ATP synthesis linked to the oxidation of pyruvate in bromide-containing medium (o).

4; Aldridge \& Street, 1971) than they are in the presence of nitrate and isethionate ion (Figs. 3 and 5). In media that contain nitrate and isethionate ion, inhibition of ATP synthesis by triethyltin is clearly related to the saturation of mitochondrial binding site 1 (Fig. 5).

Those anions that caused increased mitochondrial sensitivity to triethyltin share the common property of making triethyltin more lipid-soluble (Fig. 1) and also participate in a triethyltin-stimulated anionhydroxide ion exchange across mitochondrial membranes (Selwyn et al., 1970a; Stockdale et al., 1970). This exchange has been reported to be responsible for the stimulation of mitochondrial respiration by trialkyltins (Stockdale et al., 1970) and thus responsible for the small amount of uncoupling observed in the presence of these compounds (Aldridge \& Street, 1971). Triethyltin does not stimulate mitochondrial respiration (Table 2) or ATP hydrolysis (Fig. 2) in nitrate- or isethionatecontaining media, and nitrate and isethionate ions

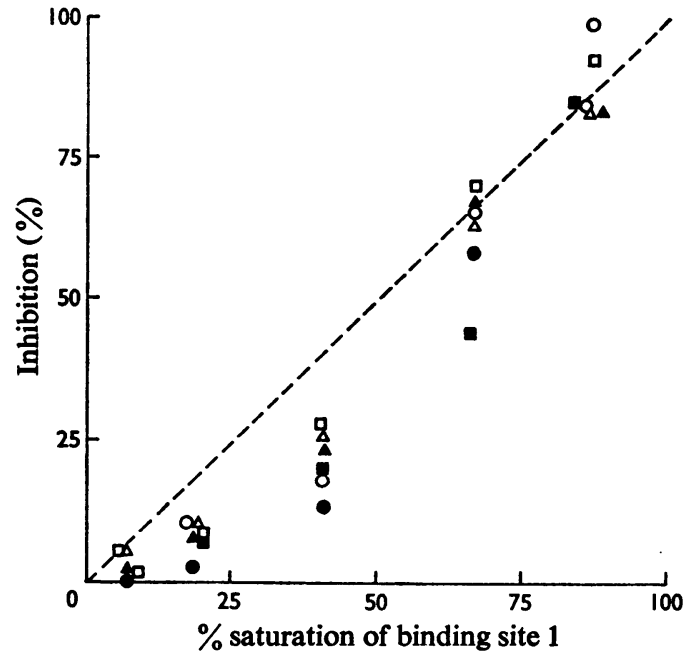

Fig. 5. Relationship between percentage inhibition of ATP synthesis by triethyltin and percentage saturation of binding site 1 in nitrate- and isethionate-containing media

ATP synthesis was measured as described in the Materials and Methods section. The symbols are as follows: inhibition of ATP synthesis by triethyltin linked to the oxidation of pyruvate in nitrate- and isethionate-containing media ( $O$ and $\bullet$ ), succinate in nitrate- and isethionate-containing media ( $\Delta$ and $\Delta$ ) and reduced cytochrome $c$ in nitrate- and isethionatecontaining media ( $\square$ and $\square$ ). The broken line shows the theoretical $1: 1$ relationship.

have no effect on the lipid-solubility of triethyltin (Fig. 1). These observations, together with the work of Selwyn et al. (1970a) and Stockdale et al. (1970), agree with the idea that nitrate and isethionate ions do not participate in a triethyltin-stimulated anionhydroxide ion exchange.

As the binding of triethyltin to mitochondria is unaffected by these different anions, another factor must be responsible for the different response of mitochondria to triethyltin on changing from halideand thiocyanate-containing media to nitrate- and isethionate-containing media. This factor might be the triethyltin-stimulated anion-hydroxide ion exchange that occurs in halide- and thiocyanate-containing media, but which might not occur in nitrateand isethionate-containing media. In the presence of these latter media, and presumably in the absence of anion-hydroxide ion exchange, triethyltin behaves as expected of an inhibitor of energy conservation, i.e. in an oligomycin-like way.

It is particularly noteworthy that 2,4-dinitrophenolstimulated respiration is insensitive to triethyltin in

Vol. 127 


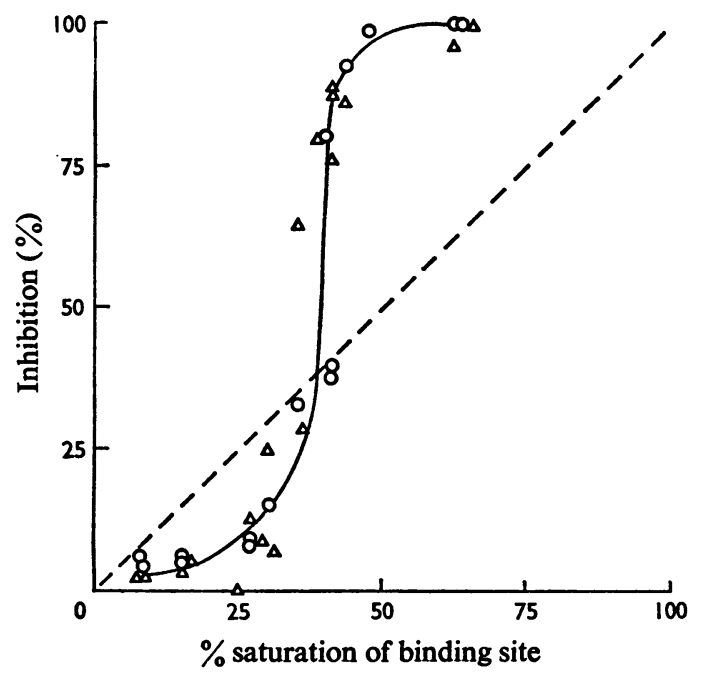

Fig. 6. Relationship between percentage inhibition of 2,4-dinitrophenol-stimulated ATP hydrolysis by triethyltin and percentage saturation of binding site 1 in nitrate- and isethionate-containing media

The results were obtained as described in the Materials and Methods section. Results were obtained in nitrate-containing media (o) and isethionate-containing media $(\Delta)$. The broken line shows the theoretical $1: 1$ relationship.

the presence of nitrate or isethionate ions but very sensitive in the presence of halide or thiocyanate ions (Fig. 3). The inhibition of this particular mitochondrial function is presumably entirely due to the anion-hydroxide ion exchange and completely unrelated to triethyltin binding.

Coleman \& Palmer (1971) have confirmed the insensitivity to triethyltin of mitochondrial 2,4dinitrophenol-stimulated respiration in a sucrose medium (Stockdale et al., 1970). From the effects of $\mathrm{pH}$ on the pattern of inhibition caused by triethyltin in a chloride-containing medium, they postulate that more than one type of binding group may be involved in the action of triethyltin. One of the activities measured (the synthesis of ATP linked to the oxidation of ascorbate) is almost certainly effected by binding of triethyltin to mitochondrial binding site 1 (Aldridge \& Street, 1970, 1971; Fig. 5). As shown by Coleman \& Palmer (1971) this inhibition is decreased by decreasing $\mathrm{pH}$ over the range 7.6-6.8, and this pattern is that which would be expected if the binding of triethyltin to mitochondria has the same characteristics as the binding of triethyltin to rat haemoglobin (Rose, 1969). In contrast, the inhibition by triethyltin of $\mathrm{O}_{2}$ uptake stimulated by 2,4-dinitrophenol increased with decreasing $\mathrm{pH}$. This inhibition has been shown here to be unrelated to the binding of triethyltin to site 1 and presumably due to anionhydroxide ion exchange. It therefore seems likely that the effect of $\mathrm{pH}$ on this inhibition reflects the effect of $\mathrm{pH}$ on the chloride-hydroxide ion exchange, which apparently has a similar pH-dependence (Fig. 2 of Coleman \& Palmer, 1971).

The mechanism by which the triethyltin-mediated anion-hydroxide ion exchange inhibits uncouplerstimulated respiration and increases the sensitivity to triethyltin of ATP synthesis linked to the oxidation of pyruvate and succinate and ATP hydrolysis stimulated by uncouplers remains to be elucidated. However, proton or hydroxide ion movement has been demonstrated to be part of mitochondrial substrate transport (Quagliariello et al., 1971; Papa et al., 1971; McGivan \& Klingenberg, 1971; Aleksandrowicz \& Swierczynski, 1971). If a hydroxide ion gradient was a necessary requirement for substrate transport, then the triethyltin-mediated anionhydroxide ion exchange might inhibit substrate transport by equilibrating hydroxide ions across the membrane. An effect of triethyltin on substrate transport has been observed (Manger, 1969), but the effect was overcome by increasing substrate concentration. The medium used by Manger (1969) contained low concentrations of chloride, however, and mainly contained $0.25 \mathrm{M}$-sucrose.

The work of Stockdale et al. (1970) and Selwyn et al. $(1970 a)$ has been extended in the present study and indicates that triethyltin may influence oxidative phosphorylation in two ways: one associated with a halide ion-hydroxide ion exchange and the other by binding to a component involved in the energyconservation mechanism. The original postulate of an energy-transfer chain (Aldridge \& Rose, 1969) was based on the assumption that triethyltin brought about all its effects by a single mechanism (i.e. binding to site 1). This assumption is invalid and the postulate must be abandoned. Inhibition of ATP synthesis in nitrate- or isethionate-containing media, in which an anion-hydroxide ion exchange probably does not occur, bears a 1:1 relationship to complexing of binding site 1 . This can be interpreted to mean that all three coupling sites in the electron-transport chain operate through a single enzymic site for the synthesis of ATP. On the basis of the present evidence, at least part of this site is likely to consist of histidine residues (Rose, 1969; Rose \& Lock, 1970; Aldridge \& Rose, 1969).

We are grateful to Mr. B. W. Street and Mr. R. J. Price for valuable technical assistance.

\section{References}

Aldridge, W. N. (1957) Biochem. J. 67, 423

Aldridge, W. N. (1958) Biochem. J. 69, 367 
Aldridge, W. N. (1962) Biochem. J. 83, 527

Aldridge, W. N. \& Cremer, J. E. (1955) Biochem. J. 61, 406

Aldridge, W. N. \& Rose, M. S. (1969) FEBS Lett. 4, 61

Aldridge, W. N. \& Street, B. W. (1964) Biochem. J. 91, 287

Aldridge, W. N. \& Street, B. W. (1970) Biochem. J. 118, 171

Aldridge, W. N. \& Street, B. W. (1971) Biochem. J. 124, 221

Aleksandrowicz, Z. \& Swierczynski, J. (1971) FEBS Lett. 15, 269

Coleman, J. O. D. \& Palmer, J. M. (1971) Biochim. Biophys. Acta 245, 313

Fiske, C. H. \& SubbaRow, Y. (1925) J. Biol. Chem. 66, 375

Holland, P. C. \& Sherratt, H. S. A. (1971) Biochem. J. 121, 42P

Manger, J. R. (1969) FEBS Lett. 5, 331
McGivan, J. D. \& Klingenber g, M. (1971) Eur. J. Biochem. 20, 392

Papa, S., Francavilla, A., Paradies, E. \& Meduri, S. (1971) FEBS Lett. 12, 285

Quagliariello, E., Genchi, G. \& Palmieri, F. (1971) FEBS Lett. 13, 253

Robinson, H. W. \& Hogden, C. G. (1940) J. Biol. Chem. 135, 707

Rose, M. S. (1969) Biochem. J. 111, 129

Rose, M. S. \& Aldridge, W. N. (1968) Biochem. J. 106, 821

Rose, M. S. \& Lock, E. A. (1970) Biochem. J. 120, 151

Selwyn, M. J., Dawson, A. P., Stockdale, M. \& Gains, N. (1970a) Eur. J. Biochem. 14, 120

Selwyn, M. J., Dawson, A. P. \& Dunnett, S. J. (1970b) FEBS Lett. 10, 1

Sone, N. \& Hagihara, B. (1964) J. Biochem. (Tokyo) 56, 151

Stockdale, M., Dawson, A. P. \& Selwyn, M. J. (1970) Eur. J. Biochem. 15, 342 